\title{
School Improvement through Government Agencies: Loose or Tight Coupling?
}

Introduction

Many governments are seeking to improve their school systems so that their countries can compete effectively in an increasingly global economy. The advent of comparative studies of student performance, notably the Programme for International Student Assessment (PISA), means that differences in learner outcomes are transparent, leading to pride or disappointment, depending on national rankings.

In seeking to improve student outcomes, governments may choose to exercise direct control over schools, as in many centralised systems, or to provide frameworks for intermediate bodies to engage in improvement activities. Although political and professional structures are often in place, at state, provincial or local government levels, some countries have also chosen to implement their policies through agencies. Examples of such bodies are the National College for School Leadership (NCSL), now the National College for Teaching and Leadership (NCTL) in England, and the Institut Aminuddin Baki (IAB) in Malaysia.

The Department of Education of the South Africa province of Gauteng (GDE) has also chosen to implement its school improvement programmes partly through two specialist units, the Sci-Bono Discovery Centre, which focuses on maths, science and technology, and the Matthew Goniwe School of Leadership and Governance, which specialises in school leadership, management, governance and teacher development. The purpose of this paper is to report on an evaluation of the work of these two bodies, commissioned by the $\mathrm{GDE}^{1}$ as part of its 20th anniversary commemorations. The paper examines these organisations' origins and purposes, governance, activities, achievements and impact through an analysis of relevant documents and interviews with eleven key actors in the operation of these specialist bodies.

\section{Conceptual Framework}

The notion of loose coupling seems particularly appropriate as the conceptual framework for this paper. It is strongly associated with the work of Karl Weick, who argues that organisations are characterised by fragmentation and loose coupling. 'By loose coupling, the author intends to convey the image that coupled events are responsive, but that each event also preserves its own

\footnotetext{
${ }^{1}$ The ideas in this paper are those of the author, not the GDE
} 
identity and some evidence of its physical or logical separateness' (Weick 1976: 3). Weick (1976) also links loose coupling to decentralisation. He argues that decentralisation avoids the delays and uncertainties associated with centralised decision-making. A loosely coupled system can help to avoid weaknesses in one part of the organisation by 'sealing off' the breakdown.

Orton and Weick (1990: 203) claim that the concept of organisations as loosely coupled is widely used, diversely understood and underspecified. They point to three causes of loose coupling; causal indeterminacy, fragmentation of the external environment, and fragmentation of the internal environment. The fragmentation of the external environment is the element most relevant to this paper and this arises from dispersion and incompatible expectations. Loose coupling provides the opportunity to accommodate differing expectations through a buffering process.

Several commentators (e.g. Boyd and Crowson 2002, Fusarelli 2002, Goldspink 2007, Meyer 2002, Rowan 2002) point to the trend towards tighter coupling, linked to 'new managerialism' and the standards agenda, as governments seek to impose their policy agendas on educational organisations. Meyer (2002), for example, notes the normative tone of much writing on loose coupling and questions its relevance for what seem to be increasingly bureaucratised education systems. Hierarchies are resilient as noted, for example, by Boyd and Crowson (2002) and Bush (2011).

Most of the literature, e.g. Lutz (1982), refers to intra-organisational loose coupling but Orton and Weick (1990) extend this to inter-organisational relationships, which is apposite for the study reported in this paper. In terms of school improvement, outsourcing certain activities to agencies can avoid the sloth and inefficiency associated with bureaucracies and potentially enables governments to achieve their aims more quickly. Paradoxically, however, governments may wish to tighten control over such agencies, in order to ensure that outcomes are in line with their expectations, as noted above.

Goldspink (2007: 28) also comments on the weaknesses of bureaucracy, which 'have been increasingly criticised for being non-responsive and inefficient means for organising public administration'. Loosely coupled systems operate in a different way, with multi-dimensional professional relationships, rather than hierarchical control. He notes, echoing Orton and Weick (1990), that loosely coupled organisations provide adaptability and 'buffering', valuable features for governments seeking responsiveness rather than bureaucracy. Goldspink (2007: 43) also refers to the benefits of 'arms length' or devolved institutional arrangements. These include greater potential 
for creativity and independent thought. Although the link is not explicit, these ideas appear to have informed the decision of the GDE to establish, and to expand, Sci-Bono and MGSLG.

\section{Research Design and Methods}

The author was commissioned by the GDE to conduct an evaluation of Sci-Bono and MGSLG. It was not possible to visit South Africa for this purpose, so data were collected through documentary analysis and telephone interviews. Fitzgerald (2012) stresses the value of documentary research because they provide a permanent account of events. The GDE made available its archive of documents from the past 20 years and the author chose to examine all such papers related to the two bodies, as well as relevant GDE documents.

Documentary analysis was supplemented by interviews with 11 key stakeholders. Five interviews were conducted with 'information rich' participants in each organisation, using parallel purposive sampling. The participants comprised the CEO, three other staff, and one long-serving member of the Board of Directors in each body, identified in this paper as Sci-Bono 1-5 and MGSLG 1-5, to preserve confidentiality. The author also interviewed one senior official of the GDE (GDE 1). This person was chosen because of their responsibility for working with the two organisations. The author developed three semi-structured interview schedules, customised for each organisation but with sufficient commonality to allow for cross-case comparisons.

\section{Findings}

\section{Origins and purposes}

Matthew Goniwe School of Leadership and Governance (MGSLG) was opened in 2003. Its website states that its aims are:

- To provide a central hub for the professional growth of school leaders and governors.

- To design and present cutting edge school leadership, governance and management training programmes.

- To focus on improving practice through research.

The website adds that MGSLG's main objective is to develop high order leadership and governance skills and qualities underpinned by critical reflection based on a body of relevant leadership and governance theories and concepts. Its target clients are principals, deputies, HoDs, district officials and school governing bodies (SGBs). 
MGSLG's initial brief for school leadership, management and governance has been modified and extended to include teacher development. This is not reflected in MGSLG's stated aims (see above) but has significant implications for its focus, activities and target clients.

The GDE official states that the teacher development brief links to the national teacher development framework, which includes the establishment of provincial institutions and centres for teacher development. There are draft national norms and standards for such institutes and centres. The official adds that there have been some 'teething problems' for MGSLG in adapting to this new role.

There are different views among MGSLG senior staff about whether GDE and MGSLG goals are aligned. MG1 states that the founding goals of MGSLG align well to GDE's strategic goals, for example in respect of research and programme development for schools. MG3 also believes that the goals are well aligned. The GDE wants to have effective schools, with good leadership and good classroom teaching. MG2 agrees that goals are aligned but adds that roles and responsibilities are not clarified and this leads to tension. In particular, the new mandate for teacher education has heightened tension. MG4 argues that the current goals of MGSLG are 'totally unaligned' with its original mandate. Previously, it was semi-autonomous but it now responds directly to the mandates of the GDE. Linked to this point, MG1 comments that there should be a stronger focus on MGSLG as an advisory institute as well as being responsible for project delivery; a two-way street with a feedback loop, not just a one-way street. The Board director claims that there is now stronger alignment between the goals of GDE and MGSLG. In particular, there is a better link between MGSLG and GDE's political leadership. The GDE official also believes that the goals are aligned.

The Sci-Bono Discovery Centre was opened in 2004 by the GDE and the private sector. Its stated purpose is to address the scarce skills needs of South Africa by contributing to the effective delivery of quality mathematics, science and technology education in all schools in the province. Its teacher development department is responsible for the training of all Gauteng maths, science and technology educators.

The work of the Sci-Bono centre is significant because secondary school education in mathematics and science poses a significant challenge for South Africa. Few students study and pass the certificate examinations in these subjects. South Africa has struggled to deliver an acceptable quality of MST education in primary or high schools (Blum et al 2010, GDE 2010, University of Pretoria 2010). 'There is a wealth of evidence that shows that our school system is failing our children in respect of MST education' (GDE 2010: 4).

The GDE's MST Improvement Strategy has four objectives: 
- To strengthen MST teaching in all Gauteng schools

- To improve the provision of MST resources

- To provide programmes of learner support in MST

- To improve the management of MST teaching and learning

(GDE 2010: 5-7).

The Sci-Bono Discovery Centre has what is described as 'a strong co-ordinative role' (GDE 2010: 7). Sci-Bono's own goals link to the GDE objectives:

- To improve teaching and learning of mathematics, science and technology in Gauteng schools.

- To provide career education to all learners in Gauteng.

- To promote and improve public awareness of, and engagement with, science, engineering and technology.

All Sci-Bono interviewees refer to close alignment between the goals of the GDE and Sci-Bono. This is unsurprising given that the latter is the creature of the GDE, is largely funded by the parent body, and is following the former's mandates. One senior official says that Sci-Bono is 'an arm of the GDE' (SB4). Its mandate has evolved from managing traditional science centre activities to running key MST (maths, science and technology) and learner improvement programmes for the GDE (SB4). It may be regarded as a 'directorate' (SB4) of the GDE, leading GDE's MST strategy but this leads to some ambiguity about its status; 'when are we part of the GDE and when are we independent?' (SB1). SB1 adds that 'Sci-Bono cannot exist without the GDE'. The director (SB5) comments that the Board has had a lot of debate about Sci-Bono's new mandate, to develop and deliver the maths and science strategy, and about the nature of its accountability for this strategy. The GDE participant adds that Sci-Bono experienced some 'teething problems' in adapting to its teacher development role from 2010.

\section{Governance}

Loose coupling between the two bodies and the GDE is achieved partly by their governance arrangements. Both organisations have a Board of Directors which act, to some extent, as the interface between senior managers and GDE officials. The Sci-Bono Board has ten members. Its strategic plan (2013-2016) notes that it is legally an independent organisation but, in reality, 'it currently exists at the pleasure of GDE, funding from which Sci-Bono fully depends on (Sci-Bono 2013: 18). This document also points to numerous risks arising from the GDE relationship, including 
funding lags, challenges to capacity arising from large projects, and the way in which the relationship undermines the Sci-Bono Board's capacity to function independently (Ibid: 19).

As implied above, there is a contradiction between the formal status of Sci-Bono, as a legally independent company, and the operational reality; GDE 'almost instructs us' (SB4) and the two bodies are financially 'joined at the hip' (SB2). SB1 asks whether it would be better for Sci-Bono to be truly independent or to be more tightly linked with GDE as an agency, with a regular income? The director says that, in respect of GDE work, the Board's role is largely fiduciary but it takes full responsibility for the Science Centre.

MGSLG is a section 21 company governed by a Board of Directors. The current Board comprises eight members. The role of the Board links to MGSLG's relationship with the GDE and the extent to which a section 21 company providing vital GDE services should be, and be perceived to be, independent of its parent body. An evaluation by the University of the Witswatersrand (2009) summarises this dilemma:

'Created by the Gauteng Department of Education (GDE), MGSLG was founded as a Section 21 company to provide a certain level of independence and autonomy. But, with a Board of Directors chosen by, and largely populated by the GDE, MGSLG was intended to have a close relationship to the working of the Department' (WITS 2009).

The WITS (2009) evaluation also refers to lack of clarity about the Board's role, and to role conflict arising from GDE membership of the Board. These challenges are reiterated in MGSLG's (2011) strategic plan and remain central issues for the GDE and for MGSLG. A tight relationship with the Department provides the best prospect of GDE policies being implemented effectively. However, a degree of independence is essential to encourage innovation and to widen inputs about educational development. The National College for Teaching and Leadership (NCTL), formerly the National College for School Leadership (NCSL), in England faces a similar challenge and the Government has recently converted NCTL from a semi-independent body, with a governing board, to a government agency, with no board. This change can be seen as a shift from loose to tight coupling.

The role of the Board, and its relationship to MGSLG, and to the GDE, was addressed by all five MGSLG interviewees. The Board director notes that the original Board was semi-independent but then it became more GDE-dominated. Latterly, it has only independent members but these are appointed by the political leader and serve 'at the MEC's pleasure'. The Board's role is mainly about audit and financial oversight, a view confirmed by the GDE official. The MGSLG interviewees largely confirm the director's view about Board membership and responsibilities but MG4 argues that Board 
independence is compromised by the MEC's role in appointing its members. The Board director adds that independence is also compromised by MGSLG's dependence on GDE funding.

The governance arrangements provide the potential for the buffering role suggested by Goldspink (2007). However, this is compromised by the political leader's control over Board membership and by the organisations' financial dependence on the GDE. While the two Boards can operate as a link between the GDE and the two organisations, this may be little more than a fig leaf to conceal GDE control.

\section{Activities}

Sci-Bono's activities arise from its goals. The Centre's activities have grown significantly since it opened nine years ago. For example, Discovery Centre visitor numbers grew from 24,000 in 2004 to 240,000 in 2012, a tenfold increase (Sci-Bono 2013: 53). The outreach programme also grew and, by 2012 , worked with 100,000 learners. Other major activities include exhibits, MST programmes, teacher support, and careers education, and the strategic plan foreshadows increases increased activity in all these areas (Sci-Bono 2013: 56). Sci-Bono also manages the GDE's MST strategy. This includes two main interventions:

- Secondary School Improvement Programme (SSIP), which involves supporting 366 high schools.

- Gauteng Provincial Literacy and Mathematics Strategy, which involves teacher professional development and distribution of teaching and learning resources to 811 priority primary schools.

SB2 says that Sci-Bono's activities are decided jointly by its Board and the GDE. SB4 adds that the GDE has always 'had a say' but has become more powerful in recent years. Sci-Bono could not survive in its current form without GDE funding - 'it would become significantly smaller' (SB4). SB2 claims that 'Sci-Bono can act more quickly (than GDE) without formal protocols and with greater value-for-money'. The Director (SB5) comments that 'GDE leaders decide what Sci-Bono will do; it is effectively a project management agency'. Sci-Bono's traditional activities, which emanate from its Board, are greater in number, but the projects requested by the GDE are much bigger with substantially more funding (SB4). This inevitably places Sci-Bono in a subordinate position.

MGSLG's activities include professional development activities for principals, deputies, HoDs, district officials and SGBs. However, these activities have changed significantly since it opened in 2003 . The 
strategic plan (MGSLG 2011) refers to seven activity areas arising from its mandate. Three of these are consistent with its aims:

1. Management and leadership development to support schools and district offices

2. School governance development and support

3. School and district improvement programmes

The other four programme areas illustrate a significant extension of its role into teacher education and family support. These changes arise from discussion with the GDE, and especially its political leader.

1. Teacher development on policy, curriculum content and pedagogy

2. Pre-grade $\mathrm{R}$ and grade $\mathrm{R}$ development and support for practitioners

3. Facilitation and family support in education through dialogue

4. Effective partnerships and stakeholder management

The addition of teacher development, in particular, is a major change, which began with its role in NCS and curriculum training. The WITS (2009) evaluation shows that this change divided opinion:

'There was considerable difference of opinion about the selection of MGSLG to conduct this training ... [some] feared that this award was a dangerous expansion into areas that were not directly related to its original mandate' (WITS 2009: 6).

'If you were to teach people to lead institutions - you need to understand what happens in the classroom between learner and teacher - you should not divorce this from what you do for principals' (GDE official, cited in WITS 2009: 7).

These extracts provide two distinct views on MGSLG's expanded mandate. If school leadership is primarily about leadership for learning, as some would argue (see Bush 2013a), then the extension of MGSLG's role is logical but it should then be reflected in its aims. However, there is also a risk that its original distinctive mission will be blurred.

MGSLG interviewees expressed a range of views about this key issue. MG1 says that the addition of teacher development is 'more than welcome'. Leadership is not just for principals but also has a classroom dimension - teacher leadership. Similarly, MG3 notes that it is a 'beneficial change' which expands MGSLG's mandate and provides the prospect of holistic development for teachers, focusing on the 'nuts and bolts' of teaching as well as leadership and governance. The rationale arises partly from the 'not pleasing' performance of South African learners in international tests. 
MG2 states that adding teacher professional development to MGSLG's mandate is a 'good move' because all relevant programmes can be integrated. MG4 claims that MGSLG is not fulfilling its original mandate but is now focused on teacher development. This is project management, not 'original thinking', and MGSLG is 'neglecting school leadership'. The director agrees that teacher development was not part of MGSLG's original mission and adds that the Board has asked questions about 'mission drift'. The director adds that management work is 'tailing off'. However, the GDE official notes that the changes arise from a national mandate and summit on teacher development.

These comments provide more evidence about the nature of coupling between GDE and the two school improvement bodies. 'Project management', mentioned by participants from both organisations, suggests a tightly coupled relationship while the comment about acting quickly without formal protocols may suggest a looser relationship or just a device to circumvent bureaucratic delays.

\section{$\underline{\text { Achievements and development needs }}$}

Sci-Bono has grown very quickly since its establishment and can claim a number of achievements. SB2 is proud of evolving a model for the Science Centre which does not exist elsewhere, notably in its support for mainstream schooling. SB1 points to the success of the extended teacher professional development programme, covering subject knowledge, pedagogy and assessment, with teachers out of school for three weeks, with substitute teachers employed. SB4 comments on the value of the SSIP, the exhibits collection, the large number of programmes, which 'engage learners', and the careers guidance programme. Significantly, SB3 is proud of the successful project management of the SSIP, with effective systems, clean GDE audits, and improved matric pass rates.

Despite these perceived achievements, the rapid growth of Sci-Bono, from 27 staff and a R12million budget, to 240 people and a R300 million budget, has led to concerns about the sustainability of the organisation (SB2, SB3, SB4). Its heavy dependence on GDE funding leads to anxiety about its future shape and size, especially if political change leads to a different view about its role and scope. Two senior staff (SB3 and SB4) are also concerned about recruitment and succession planning, given the quality criteria and the national skills shortage in science and technology. The overarching development need is to clarify Sci-Bono's relationship with GDE; 'should it be more independent or more integrated?', or maintain its current 'semi-detached' status (SB3). The director (SB5) adds that Sci-Bono's stability is limited by short-term political and funding issues. In relation to teacher professional development, the respective roles of Sci-Bono and the GDE's teacher development section need to be clarified. 
MGSLG has also expanded its activities significantly and this alone could be seen as an achievement. MG3 points to the scale of its professional development programmes, with 1600 early childhood specialists completing training and 36,000 teachers trained to implement the new curriculum. MG2 claims that it has broadened its scope from training to capacity building and adds that project management, linked to specific standards, is an achievement.

MG1 refers to several achievements, including a stronger strategic focus, resolution of previous financial problems, and improved staff morale. There has been a move away from a 'conveyor belt' 'delivery model' towards a capacity building approach. However, MG4 argues that its achievements are limited by having to serve GDE mandates rather than being semi-autonomous. The director says that MGSLG is 'an efficient arm of the state' with a good record of delivering basic services, better than the GDE itself. However, there is limited evidence to make strong claims about its effectiveness.

Despite these reported achievements, MG3 says that teacher attendance at professional development events is variable while MG1 believes that recent policy changes in respect of continuing professional development (CPD) should help teachers to be well motivated to undertake training rather than being reluctant to do so. MG3 notes that trainers and facilitators require more training. This links to MG2's view that more work is required to develop materials and to provide high quality facilitation. MGSLG is also developing a longer-term approach to projects, not one-off workshops.

MG1 makes wider points about development, noting an ambition for MGSLG to become a 'centre for excellence' and to develop district support programmes, which were provided in the mid-2000s. The director says that MGSLG needs to clarify and stabilise its mandate but MG4 argues that it needs to regain some autonomy, not just respond to GDE. This final comment provides further evidence of the challenges involved in sustaining a degree of independence when the GDE appears to set the agenda, and to determine the bodies' funding.

The achievements of the two bodies are significant, notably in a substantial increase of scale and in its diversification to meet political and bureacratic imperatives. It appears unlikely that these gains could have been achieved without the flexibility and responsiveness conferred by their semiautonomous status but this is clearly a double-edged sword as their original mandates are being compromised by the requirement to lead the GDE's teacher development initiative.

The comments about the achievements of the two organisations constitute 'self-reporting' and comprise perceptions rather than verifiable data. Given their substantial extended role, it seems to 
be important for the impact of their activities to be evaluated regularly and thoroughly. This is acknowledged in MGSLG's (2011) School Capacity Building Model which asks the key question; 'monitoring, evaluation and support - how well are we doing?' Its SWOT analysis (ibid: 4) also refers to 'a lack of evaluation of impact of programmes'. There have been programme evaluations, for example of the training programme for ISDOs (SAIDE 2006), of SGB training (CEPD 2011), and of the ACE: School Leadership programme (Bush et al 2012), but this area seems to require specific capacity.

Interviewee comments on the impact of MGSLG include views about the process and about the nature of impact. MG2 says that impact is assessed by including a research component within all projects. For example, the project on SMTs, delivered by the three HEIs, has an independent company conducting an evaluation, including a baseline phase. MG1 notes that MGSLG assesses the impact of materials and of the trainers. MGSLG has also enhanced its monitoring ratio to assess delivery.

MG3 says that monitoring is based largely on 'rather anecdotal' teacher feedback. There are plans to commission an independent evaluation of teacher professional development activities. The director comments that there is 'no concrete evidence' that MGSLG has made a big impact in schools. Services have been provided, and money has been spent as intended, but it is hard to judge its effectiveness. Similarly, the GDE official notes that assessment of impact is 'missing' and will be a major focus in the future.

A related issue concerns whether MGSLG has achieved its intended focus to improve practice through research. The initial structure had a 'research and school improvement' directorate but this was closed several years ago. A strategic imperative for MGSLG's Board, and for the GDE, is whether it should be involved in research and knowledge creation and dissemination, as its aims imply. If so, MGSLG's structures and processes need to reflect this emphasis, a point acknowledged in its strategic plan (MGSLG 2011: 9 \& 17). This could be reflected in a research and evaluation directorate, for example.

Sci-Bono (2013: 71) recognises the importance of impact measurement and assessment and its strategic plan states that it's 'credibility depends on its ability to measure its effectiveness'. SciBono's (2012) Monitoring and Evaluation report provides an overview of its internal monitoring and evaluation. The report covers the Careers Centre, School Support, including the SSIP, the Science Centre, and Teacher Development. Evaluation methods include surveys (career centre, science centre), analysis of client records (career centre), learner interviews (school support), educator 
interviews (teacher professional development), pre- and post-testing (school support, teacher professional development), and learner tracking (teacher professional development). These are appropriate evaluation tools but samples were sometimes very small and internal monitoring is not a satisfactory substitute for robust external evaluations.

SB2 says that monitoring and evaluation of some projects was introduced 'from the beginning' but this was more difficult for some other activities. The director (SB5) adds that impact evaluations 'are not where they should be' but some processes are in place. SB2 confirms the use of the evaluation methods outlined above but adds that it remains difficult to judge the academic value of certain interventions, for example the exhibits and the careers centre. There are also political aspects of evaluations. For example, learner progress cannot be wholly attributed to Sci-Bono, as this would undervalue the contributions of teachers.

SB4 states that the School Support Improvement Programme (SSIP) has been acknowledged as the key programme responsible for improved grade 12 pass rates in Gauteng. In 2012, the CEO was given a special award by the MEC for Sci-Bono's contribution to improved matric results, a tangible acknowledgement of the impact of its programmes.

Providing verifiable evidence of the impact of their programmes would be a powerful tool to secure the future of these two school improvement bodies. This seems to be 'work in progress'. The rapid increase in the scale of their activities provides evidence of reach but it is more difficult to make a confident judgement about the quality of their work.

\section{Overview}

Both these bodies are relatively new but they are playing an increasingly important role in implementing the GDE's school improvement and teacher professional development strategies. They are nominally independent organisations, but rely on the GDE for most of their funding. The goals are closely aligned, partly because the two organisations are effectively the project managers for GDE programmes but there is concern about 'mission drift' away from their original focus on leadership and governance, and science education, towards a wider teacher development role. The role of the Boards of Directors is affected by the political leader's power to appoint their members and by their dependence on GDE funding. The Boards' roles are also ambiguous because GDE mandates effectively by-pass the Board. Significantly, the GDE official has little contact with the Boards, dealing directly with the managers. The two bodies appear to have been effective in delivering GDE-mandated programmes, notably in respect of meeting ambitious targets about the number of participants, but there are anxieties about their ability to influence the agenda rather 
than simply implementing GDE imperatives. Greater clarity is also required about whether their teacher professional development role has served to limit, and to undermine, their initial sharp focus on leadership and governor development, and on science education.

\section{Discussion}

The relationship between the two school improvement agencies and the provincial government, represented by the GDE, provides insights into how loosely coupled organisations may be able to achieve goals which would not be possible through conventional bureaucracies within the same timescale, or at all. This section examines the nature of the coupling process and the benefits and challenges conferred by these arrangements.

\section{Buffering}

The literature (e.g. Orton and Weick 1990, Goldspink 2007) stresses that agencies working in a loosely coupled environment are able to interpret government imperatives rather than simply implementing them, providing a two-way relationship rather than a simple top-down model. The main structural features underpinning buffering in Gauteng are the boards of directors of MGSLG and SciBono. Both boards are legally independent but this autonomy is compromised because the minister appoints board members and because both organisations are dependent on government for most of their funding. In respect of the large-scale teacher development initiative, the GDE largely bypassed the boards by engaging directly with the CEOs and other senior staff. Buffering is limited by the direct control sought by government, a shift along the continuum from loose to tight coupling, echoing the points made in the literature (Boyd and Crowson 2002, Fusarelli 2002, Goldspink 2007, Meyer 2002, Rowan 2002) about the impact of new managerialism on inter-organisational relationships. - The trend towards project management of government initiatives suggests tighter coupling for these agencies than originally intended.

\section{$\underline{\text { Values }}$}

Loose coupling provides the 'space' to allow different interests and values to co-exist without coming into direct conflict. SciBono attracted staff who are committed to mathematics, science and technology education. Similarly, MGSLG recruited staff interested in leadership development and school governance. These professional values are very different from the managerialist values implicit in bureaucratic organisations (Boyd and Crowson 2002, Bush 2011). The introduction of a large-scale teacher development programme changed the raison-etre of the organisations in a significant way, compromising the values of some senior staff and creating discomfort, as noted in the perceptions of some participants. 


\section{Fragmentation}

Orton and Weick (1990) point to internal and external fragmentation as causes of loose coupling but, in the South African case, they may be more readily understood as features of loosely-coupled relationships between organisations and key individuals within them. While MGSLG and SciBono are creatures of GDE, they developed their own values and purposes in their formative years. While operating in accordance with government desiderata, these were not tightly specified and the two organisations were largely able to determine for themselves how to develop school principals, train school governors, and enhance learning in STEM subjects. As noted above, the boards of directors provided a degree of protection from direct intervention by government, a mode of external fragmentation. However, as noted by both CEOs, attempts to tighten links, and to reduce fragmentation, meant that hierarchical controls were imposed and feedback loops were weakened. Internal fragmentation increased as the teacher development initiative came to dominate the activities of both agencies. Staff committed to the original mission of SciBono and MGSLG resented the 'intrusion' of this top-down initiative, bemoaning that it compromised their core purposes, while new staff became committed to the teacher development work.

\section{Conclusion: Loose or Tight Coupling?}

The Sci-Bono Discovery Centre and Matthew Goniwe School of Leadership and Governance are both relatively new bodies, in existence for barely half of the 20 years since South Africa's first democratic elections. They began as specialist organisations but their role has changed and expanded significantly during the past few years. The main innovation for both units is the addition of a substantial teacher development role to their previous activities. The driver for this change appears to be partly the current political leader and partly a response to national policy, notably the national teacher development framework. The decision to allocate these responsibilities to Sci-Bono and MGSLG can be understood via the 'garbage can' model of decision-making (Bush 2011, Cohen and March 1986). In this model, 'problems' are attached to pre-existing 'solutions'. Sci-Bono and MGSLG were already operational and appeared to provide ready-made 'solutions' to the 'problem' of teacher development. It is not clear whether the establishment of a separate teacher professional development unit was considered and, if so, why this option was rejected.

There are mixed views about whether the teacher development role compromises the original mandate of the two organisations or serves to enhance it. There are concerns about 'mission drift', limited capacity, overlaps with the GDE teacher development function, and the shift to a project 
management role, focusing on delivery of GDE and national mandates, rather than responding directly to teacher, leader and governing body development needs.

A related issue concerns the relationship between the GDE and the two organisations; boards and senior staff. The boards have gone through different stages but are currently 'independent'. However, this is largely notional, as their members are appointed at the MEC's discretion and their budgets are mainly dependent on the parent body. Some directors are concerned about the accountability implications of this three-way relationship and about their limited ability to influence the agenda. The relationship can be interpreted using the 'coupling' metaphor (Goldspink 2007, Weick 1976, Orton and Weick 1990), as noted earlier.

Tight coupling, common in hierarchical organisations such as government departments, means that political and bureaucratic mandates are more likely to be fulfilled. A central question, and a major concern for the participants, is whether the GDE will move towards tighter coupling in the future. If they do so, this would probably mean the abolition of the Boards of Directors, which would end any vestiges of independence. There are echoes here of the changes which occurred in the status of the English National College for School Leadership (NCSL), now the NCTL. More than a decade ago, Bolam (2004: 263) warned that 'the ongoing support and commitment of key civil servants, as well as senior politicians, is essential to the continuing success and existence of such national initiatives'. For much of its life, the NCSL had a Governing Council, which provided a 'buffering' role between government ministers and officials and the College's director and staff. In its early formative years, the NCSL claimed to be an 'independent voice of school leaders'. While this was always more rhetoric than reality, the trappings of independence were removed in 2012, when the College became an Executive Agency of the Department of Education, directly accountable to ministers (Bush 2013b). Loose coupling was replaced by tight coupling and what was once a widely respected centre for school leadership has been reduced to a shadow of its former glory. The lesson for South Africa is that political change could lead to a modified status for Sci-Bono and MGSLG. They could be 'swallowed up' by the bureaucracy, as one participant suggested.

In a loosely coupled relationship, there is scope for two-way communication between the government department and the semi-independent school improvement bodies. In Gauteng, there appears to be a tension between the project management role of Sci-Bono and MGSLG, implementing the mandates of the GDE, and the wish to influence the agenda. The MGSLG respondent's comment about the need for a 'two-way street', with a feedback loop, not just a one way street, goes to the heart of the relationship but other participants say that recent changes have compromised the semi-autonomous status these bodies previously enjoyed. If they continue to be 
governed by their Boards of Directors, rather than becoming an executive agency like the NCSL, this provides at least the possibility of retaining a degree of independence. Looser coupling recognises that expertise is widely distributed and provides greater scope for subordinate bodies to contribute to policy formation as well as to implementation. This model is not comfortable for officials used to top-down decision-making but allowing Sci-Bono and MGSLG to contribute to the agenda is the best way of making use of their specialist expertise.

\section{References}

Blum, J., Krishnan, N. and Legovini, A. (2010), Expanding Opportunities for South African Youth through Math and Science: The Impact of the Dinaledi Program, World Bank.

Bolam, R. (2004), Reflections on the NCSL from a historical perspective, Educational Management, Administration and Leadership, 32 (3): 251-267.

Boyd, W. and Crowson, R. (2002), The quest for a new hierarchy in education: From loose coupling back to tight?, Journal of Educational Administration, 40 (6): 521-533.

Bush, T. (2011), Theories of Educational Leadership and Management: Fourth Edition, London, Sage.

Bush, T. (2013a), Instructional leadership and leadership for learning: Global and South African perspectives, Education as Change, 17 (S1): 5-20.

Bush, T. (2013b), Preparing headteachers in England: Professional certification, not academic learning, Educational Management, Administration and Leadership, 41 (4): 453-465.

Bush, T., Glover, D., Joubert, R., Mbokazi, Z., Moorosi, P. and Msila, V. (2012), The Impact of the MGSLG ACE Programme, Johannesburg, MGSLG and Zenex Foundation.

Centre for Education Policy Development (2011), An Evaluation of School Governing Bodies (SGBS) and the efficacy of the Matthew Goniwe School of Leadership and Governance's (MGSLG) Training Programme in Gauteng, Johannesburg, CEPD.

Cohen, M. and March, J. (1986), Leadership and Ambiguity: The American College President, Boston, Harvard Business School Press.

Fitzgerald, T. (2012), Documents and documentary analysis, in Briggs, A., Coleman, M. and Morrison, M. (Eds.), Research Methods in Educational Leadership and Management: Third Edition, London, Sage. 
Fusarelli, L. (2002), Tightly coupled policy in loosely coupled systems: Institutional capacity and organisational change, Journal of Educational Administration, 40 (6): 561-575.

Gauteng Department of Education (2010), Gauteng Mathematics, Science and Technology Education Improvement Strategy 2009-2014, Johannesburg, GDE.

Goldspink, C. (2007), Rethinking educational reform: A loosely coupled and complex systems perspective, Educational Management, Administration and Leadership, 35 (1): 27-50.

Lutz, F. (1982), Tightening up loose coupling in organisations of higher education, Administrative Science Quarterly, 27: 653-669.

Matthew Goniwe School of Leadership and Governance (2011), MGSLG Strategic Plan 2011/122013/2014, Johannesburg, MGSLG.

Meyer, H.D. (2002), From 'loose coupling' to 'tight management'? Making sense of the changing landscape in management and organisation theory, Journal of Educational Administration, 40 (6): 515-520.

Orton, J. and Weick, K. (1990), Loosely coupled systems: a reconceptualisation, Academy of Management Review, 30 (1): 101-108.

Rowan, B. (2002), Rationality and reality in organisational management: Using the coupling metaphor to understand educational (and other) organisations - a concluding comment, Journal of Educational Administration, 40 (6): 604-611.

Sci-Bono Discovery Centre (2012), Monitoring and Evaluation Report, Johannesburg, Sci-Bono.

Sci-Bono Discovery Centre (2013?), Strategic Plan 2013-2016, Johannesburg, Sci-Bono.

South African Institute for Distance Education (2006), Report on the Evaluation of the Training Programme for Institutional Development and Support Officers, Pretoria, SAIDE.

University of Pretoria (2010), Implementation of the Further Education and Training Curriculum in Mathematics and Physical Science in the Gauteng Province, Pretoria, University of Pretoria.

University of the Witwatersrand (2009), Impact Assessment of Matthew Goniwe School of Leadership and Governance, Johannesburg, University of the Witwatersrand.

Weick, K. (1976), Educational organisations as loosely coupled systems, Administrative Science Quarterly, 21 (1): 1-19. 
